\title{
The Teaching Scheme Discussion of Clothing Production Line Training Base in Campus
}

\author{
Qi Zhao ${ }^{1, a}$, Chunnuan $\mathrm{Li}^{2, \mathrm{~b}}$ \\ ${ }^{1}$ Branch Institute of Textile and Fashion Design, Jiaxing Vocational Technical College, Jiaxing, \\ 314001, China \\ ${ }^{2}$ Branch Institute of Textile and Fashion Design, Jiaxing Vocational Technical College, Jiaxing, \\ 314001, China \\ a729805129@qq.com, bemail: 767363071@qq.com
}

Keywords: Training base; garment production lines; experimental teaching program

\begin{abstract}
In order to study how to improve the efficiency of the teaching on the production line, we carry on the research. Based on the design of Rotation time on line, teaching content, teaching methods, evaluation of different teaching methods, Through the data analysis of the experimental results, the paper concludes that it is the best rotation of changing the working content every 3-5 days, the tutors in the production lines must be the double - professional teachers, the teaching content should be mainly based on the typical style of clothing and it should combine the inspiriting mechanism and the rectifying system,
\end{abstract}

\section{Introduction}

In theory, the clothing production line plays a significant role in the teaching. Although the design of the whole production line in college is very similar to the line in the clothing factory, there are crucial differences between them. The former should organize the teaching content into projects and design the progress according to the workflow in the clothing factory [1] , it builds a real production environment for the students to learning knowledge, the operating skill and to improve their professional and comprehensive quality. [2]. However, in the real teaching process, some problems are not easy to solve, there are following several aspects:

1. Because the learning process in the production line is mainly depended on the students themselves, many people think that any teacher can undertake the work.

2. There are distinctive differences between the stitching level of the student and the skilled sewer in the clothing factory.

3. The clothing factory hope that the every student could stay in the same post and not move to the new one, or they hope that the students can watch the process of production, but not touch.

\section{The Design of Practical Teaching Method}

A. The Definition of the Concept

By the teaching method, we mean the partial reform in the teaching content, teaching method, teachers and evaluation system to the students in the practical teaching process on the clothing production line the in school.

B. The Choice of Education Subject

In order to make the different teaching methods has comparable, we make the clothing design and engineer 081 and 082 which have the same professional knowledge base the same team, and the clothing design and engineer 071 and 072 another team. As needed, we test the technical skills ( mainly is making pocket, making the collar, inserting the zipper, stitching and so on), theory ability, thesis defense level and the other skills to group the students according to the overall level in the clothing major, and do the random sampling of them as needed.

C. The Choice of Teaching Content

The principle of choosing teaching content 
1. The captivity principle: we should choose the most typical project teaching content; this content can set a good example to the other learning content.

2. The practical principle: we choose the teaching content which can form an independent check or be divided into several checks. The teaching content is practical in the evaluation process.

3. The universally suitable principle: The teaching content chosen should be suitable for need of each student engaging in the practical learning.

The design of teaching process

Analyzing the checks_—valuing the quality of the checks_—arranging the students_—doing the practical teaching__recording the situation of practical teaching_researching the result of the practical teaching__suggesting improvement.

\section{The Operation of Practical Teaching Method}

A. The Interval of Changing Working Post

In the practical teaching on the clothing production line in the vocational students of two grades of 07 and 08, we select randomly 20 students from the students who have be allowed to take part in the practical learning to work on the production line. The work content mainly is pressing the upper collar and the under collar, making the collar, stitching seam allowance of the collar, stitching the collar, making the cuff, stitching the cuff. The teacher can record the whole process of the production line, averaging all the data in the same check and get the situation as the fig. 1 and fig. 2 shown.

B. The Choice of Different Teaching Methods

The chosen teaching method in the paper

The theory teaching: on the base of projects design, taking the learning aim as carrier, we direct the students to understand the theory through the learning process, the technology documents, the quality standards, evaluation standards and so on.

Performance modeling: towards one kind of learning target, the teacher gives the demonstration in the use of tool and machine, how to operate them with safety, which makes the students get a direct perceptual knowledge.

Sampling the teaching subject and grouping

Through the knowledge and the skill fundamental examination, we choose 20 students with the similar abilities from the clothing design and engineering 081 and 082 and group them into three groups of $\mathrm{A}, \mathrm{B}$ and $\mathrm{C}$. Then we make the checks of making shirt collar, slant pocket stitching the cuff as the teaching carrier, using different teaching methods and recording the situation of their learning.

Carrying out different teaching method

Group A: we carry out the teaching method which is mainly depended on the theory. The teacher shows the final or semi-manufactures of the shirt collars to the students, and explains the production process at the same time in detail. It can be united with PPT presentations to explain the process and the key point but not to operate for the students. The students should finish the checks themselves and the teacher just records their qualification rate (The process of making slant pocket and stitching the cuff is same as the shirt's process).

Group B: we carry out the teaching method which is mainly depended on operation and demonstration. The teacher finishes the whole process of making shirt for the students expertly, making the students to watch and record the process seriously. After finishing the performance, the teacher let the students to finish the same process and records the qualification rate (The process of making slant pocket and stitching the cuff is same as the shirt's process).

Group C: we carry out the teaching method which mainly depends on the explanation combined with demonstration. Before the operation, the teacher explains the production progress, the key point and the whole quality control of the shirt. The teacher should emphasis the material and the tools needed repeatedly, knowing the learning situation of the students. In the performance process, the teacher can finish the check according to the standards, emphasizing the place where the 
students could make mistakes easily and have quality problems. After this, the students finished the checks and the teacher records the qualification rate (The process of making slant pocket and stitching the cuff is same as the shirt's process).

With the same method, we choose 20 students with the similar abilities from the clothing design and engineering 071 and 072 and group them into three groups of A, B and C. Then we adopt the different teaching methods which are familiar with the ones above and do the experiment in order to get the data. We put the comparable data together and average the data, the Comparison of results in average qualification rate of the students is show as the fig. 3

C. The Choose of the Evaluation Method

In the grade of 08, we divide the 15 students with the similar abilities into three groups, and use the different method of evaluations. For the first group, the teacher shows that she cares about them and always praises them. The teacher point out the problems existing in their work but don't tell them how to make over the problems clearly. The result is that the five students work with great zeal to finish the task, in a faster speed, with the same stitching quality. The improvement in the stitching is not evident. For the second group, the teacher neither praises nor criticizes them. They just point out the wrong operation method and show them the correct stitching method and find out that they stitch faster and get a higher quality. For the third group, the teacher adopts a harsh attitude but not to explain the stitching skills for them in time. The teacher just let the students to rework repeatedly. At last, the students in the third group don't get obvious improvement either in quality or in the stitching speed and hate the learning process on the production line.

\section{The analysis of experimental data}

\section{A. The Time Interval of Different Working Post}

We make the 20 students of two grades of 07 and 08 on the production line who finish the checks including pressing upper collar, under collar, making collar, stitching the seam allowance of the collar, stitching the collar, making the cuff, stitching the cuff and collect the average data from the students to plot to form curve as the Fig1, Fig1 2.

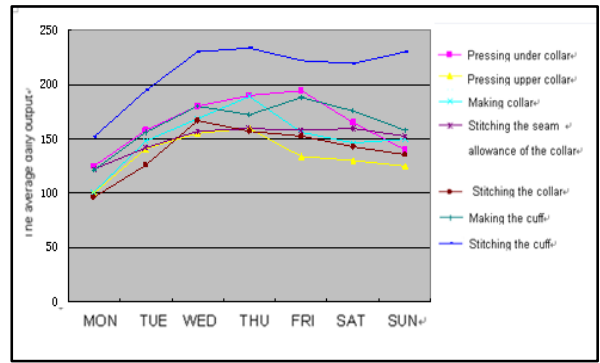

Fig 1: The average daily output of 20 students in the grade 07 in a week

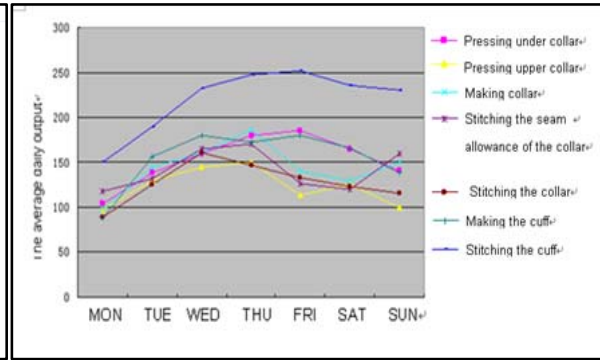

Fig 2: The average daily output of 20 students in the grade 08 in a week

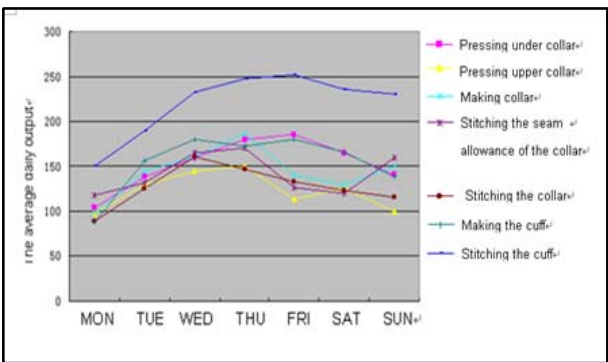

Fig 3: The comparing of average qualification rate of the production finished by the students in the two grades of 07 and 08

We can come to the conclusion that no matter the students in grade 07 or in grade 08 , the output is the highest in the middle of the week among the days in the whole week. The cause for this situation is that the students is not skillful enough at the first day of the week, they become more and more skilled from the second day, which improving the output. The students are more energetic at the beginning of the week, but they will need more rest at the end of the week which makes the students negative obviously. Almost all of the students say that they don't want to work in the same post for several weeks. So we get the result that it is best to change the students' work post every 3 to 5 days, which is suitable for the students' emotional needs and can reduce the tiredness.

\section{B. Teaching Method}

We can know from the experimental data, the improvement of the skill is not just connected with the practice. It could be get from the right guidance. Some students in the group A who have the better basement and comprehensive can do as the teacher told them, but they make many mistakes in some key point easily because they don't master the operational skills. Most of the students just finish the work as their habits and regular thinking. Every student finishes the stitching differently, 
ineffectively, slowly. The quality of the production is far away from the need of the clothing factory. Some students just don't understand how to operate but only to look at the performance process of the other people. For the students in the group of B, they don't get the help of the teacher and can't master the key point of the operation. Some of them will ask the teacher to help them, but almost of them just to finish the work on their feelings, and can't finish the work in the correct order. Some of them can only sketchily finish the work as the teacher told and the quality of more than half of the productions is not good enough. The more complex the process is, the lower the qualification rate is.

C. The Evaluation Method

Through adopting different evaluation method towards the three groups of students with the same level, we find the result that the skill learning process in the clothing production line is dynamic. So the evaluation method should be a dynamic process. Therefore, the teacher should direct the students when it is needed according to the student's learning status and personality as the requirement of the clothing factory. Because the help of the teacher can avoid the unnecessary operation mistake as possible, and improve the skill level and product quality greatly.

\section{Conclusions}

1. It is best to changing the working post every 3 to 5 days.

Based on the experimental data analysis, we find that it is best to changing the working post every 3 to 5 days. Because it is suitable for characteristics of the age, the psychology and the learning cycle of the students, it can keep the students' novelty, interests them and render the tiredness.

2. The teachers in the production line must have the double - professional teachers.

Through the analysis of the three kinds of teaching method, we can see that production line needs the teachers with the quality of professional skills and the theoretical knowledge, which is referred to the double - professional teachers.

3. In the teaching content, stress should be put on the typical style.

The typical style is summed up all the ingredients, and the knowledge in it is universal which can be easily reduced.

4. In the evaluation method, it is good to mainly adopt the process appraisal which should be combined with the encouragement and the rectifying system.

In the clothing corporations, the worst danger is to rework when a lot of clothing is be finished [5]. When the students is practicing in the production line, we should not to tell the students where the quality problem is when the clothing is finished, we should direct in the whole production process, encouraging the students and correcting the operation at the same time in order to improvement the learning efficiency.

\section{References}

[1] Jinchang Ding, Weijun Tong,The study of the production practical basement inside school[J], The study of higher education in China, Vol. 2 (2008)

[2] Yumei Xu: The study of the practical teaching in the clothing major in vocational teaching [J], The light industry in Guangxi, Vol. 12 (2008)

[3] Liangchun Wang. The studying department_- the study on the production practice basement in school [J], The vocational education in China, Vol. 24 (2008)

[4] Jiashu Liu, Han Xu. The study on the connotation and practice of production practice in vocational college [J], The education and the career, Vol. 24 (2008)

[5] Lei Wang, Xiaoxu Duan. The innovational strategy on the vocational machinery production practice in college [J], The vocational paper in Liaoning, Vol. 1 (2008) 